of course be made for the altitude of the sun and the state of the weather at the various stations.

The dark frames were numbered from I to 6 , and the plates were exposed in the order in which they had been prepared, and the development proceeded in the same order.

Much of the delicate detail of the negatives is likely to be lost by vamishing. It is therefore preferable to cover them with glass, carefully binding the edges to exclude the air ; the glass cover should not touch the film. Instead of using an ordinary plate-box for the negatives, I prefer that each plate should have a slight frame similar to an ordinary "carrier," and these frames are then placed flat on a box prepared for them.

In counting seconds it is preferable that the assistant should count consecutively throughout the totality. Supposing the eclipse to last $I 30$ seconds, by counting from $I$ to 130 the operators know exactly the point arrived at after each exposure; and this is most important towards the end, as the last plate might be spoiled by the least mistake in this respect.

Artificial light of some kind will probably be required during the totality-certainly in the dark-room. We used the ordinary railway reading lamps. Boxes open on one side were provided, and in them the lamps were fixed. These boxes effectually protected the lights-without them the candles would have been exinguished by the wind.

It is better to assume that nothing will be found at the plice of observation but water, but as in India there may be some diffeulity in obtaining that necessary article sufficiently pure for photographic purposes, it will be better to provide a small stixl, which will cost about $5 s$. At Syracuse we used rain-water, which was sufficiently pure fer the purpose.

Those accustomed to photographic work in India will be aware of the necessary precautions to be observed to prevent the plates drying. At Syracuse we kept our observatory and dark-room well sprinkled with water; and the glass plates, when they were in the dark frames, were covered on the backs with wet blotting-paper.

Much disappointment will be atoided if proper care be raken in packing the apparatus: All bottles and other glass articles should be placed in separate divisions and packed with cotton wool or paper cuttings. Packing-cases should be made very strong and bound with irion plates. By atterition to these matters the whole of the apparatus and chemicals were found on being unpacked at Syracuse to be altogether uninjured-the packing cases bear testimony to the rough usage they have undergone.

A. BROTHERS:

\section{CEIFION COLLEGE SCHOOL OF NATURAL SCIENCE}

TE have long insisted in NATURE on the extreme importance of science teaching in the higher grade schools in this country, and we are glad to find that at length its importance has begun to be recognised by the head masters themselves; so that, on the whole, the progress now being made in this direction is such that we may confidently expect that at novery distant future science instruction will be provided for in all our superior schools. Foremost, if not positively the first among the schools in Foremost, if not pore thus taught stands Clifton College, whier the able direction of the Rev. J. Percival, in which scientific study is introduced to the utmost, and keenly pursted by the boys, with the encouragement of all their masters, the latter a most important consideration, and which, we are sorry to say, we cannot assert in reference to other schools of equal pretensions. There are severat points of interest about the method of teaching at Clifton, and we are glad to have the opportunity of laying before our readers a sketch of the way in which the work there is carried on, together with a sketch of the musetrm, which, may well become the model of all school museums. Science is much indebted to Mr. Percival for the magnificent example he has set in science education.

Natural Science at this College is not a voluntary subject, but forms a regular part of ordinary school work. The boys in the two highest classes on the classical side are allowed to choose between Science and German: throughout the rest of the school some branch of science is compulsory. In the Junior School Botany is taught, in the Upper School Chemistry and Physics. The boys on the classical side receive one lecture, those on the modern side two lectures a week on each of these latter subjects. The lectures are illustrated by experiments, accurate notes are exacted from the boys, and examinations are held every fortnight or three weeks.

The accompanying is one of these fortnightly papers:MAGNETISM

I. Soft iron can never be permanently magretised, yet a piece of soft iron in contact with a magnet becomes a magnet. Why?

2. What do you understand by coercive force, and magnetic satzeration?

3. How is magnetism infuenced by heat?

4. Mention the substances which are attracted by a magnet in addition to iron.

5. State one or more of the methods by which steel bars may be magnetised.

6. What is the dectination or variation of the magnetic needle, and the present extent of it?

\section{CHEMTSTRY}

a. For First and Second Sets, Modern Side only.

I. Mention the oxygen compounds of phosphorus, and the actions of water upon them.

z. Give an account of arsenicum and its chief characteristics.

3. What are the constituents and characteristics of arseniuretted hydrogen?

4. What is "white arrsenic," and how may it be prepared?

5. You are given a liquid suspected to contain arsenic; by what means would you examine it?

f. For all other Forms.

r. Ammonia gas, and hydrochloric acid gas, are brotght into contact : what is the resulting compound, and to what may it be compared?

2. What is ammonitum? Describe the formation and appearance of ammonium amalgam.

3. What do you know of chloride of nitrogen?

4. What is nitric acid, and by what means may it be procured ?

5. State the action of nitric acid upon metals, - copper, tin, antimony, - and the general tendency of the acid。

ROTANY

Third A. and B. only. (To be written on separate paper only

I. Describe the following forms of roots:-tap, napiform, piemorse, tubercular.

2. How are fruids absorbed by the roots?

3. Show clearly the true nature of the various forms of the bulb.

4. What is a "rhizome" (or root-stock)? Compare it with a "corm."

5. Give an account of the structure of the stem in a common potato.

6. Why is it that plants and animals have a mutral dependence on each other for their life?

Special classes are formed for those who wish to go deeper into these subjects, or to take up others. Thus, there are special classes studying Chemistry, Physics, Zoology, Physiology, Botany, Physical Geography, and Civil Engineering.

Facilities are also afforded for learning science practically. In the Chemical Laboratory about twenty boys study analysis. A Physical Laboratory has been built and will be opened next September. It will accommodate about twenty pupils, and its arrangements will be based 
on those adopted at King's College, London. A large workshop fitted up with carpenters' benches, vices, and lathes has been opened this term, and is exceedingly popular. There is also a physiological laboratory, in which a few of the elder boys receive instruction in Practical Zoology and Physiology.

Marks are given for work done in all the above-mentioned classes, except in the workshop. These marks affect a boy's position in his form from week to week, and thus afford a strong incentive to careful work.

Five masters are at present engag sd in teaching science.
The taste for natural history is developed by means of the Natural History Society, the School Museum, and the Botanic Garden. The society consists of about seventy members. Its meetings are held once a fortnight, they are fully attended, and there is never any lack of papers to be read. The society is subdivided into sections, which hold special meetings and make excursions for the study of different branches of science. The first number of the Transactions has just been published. The sections are engaged in preparing lists of the fauna, flora, and mineralogy of the district. The whole society makes an expe-

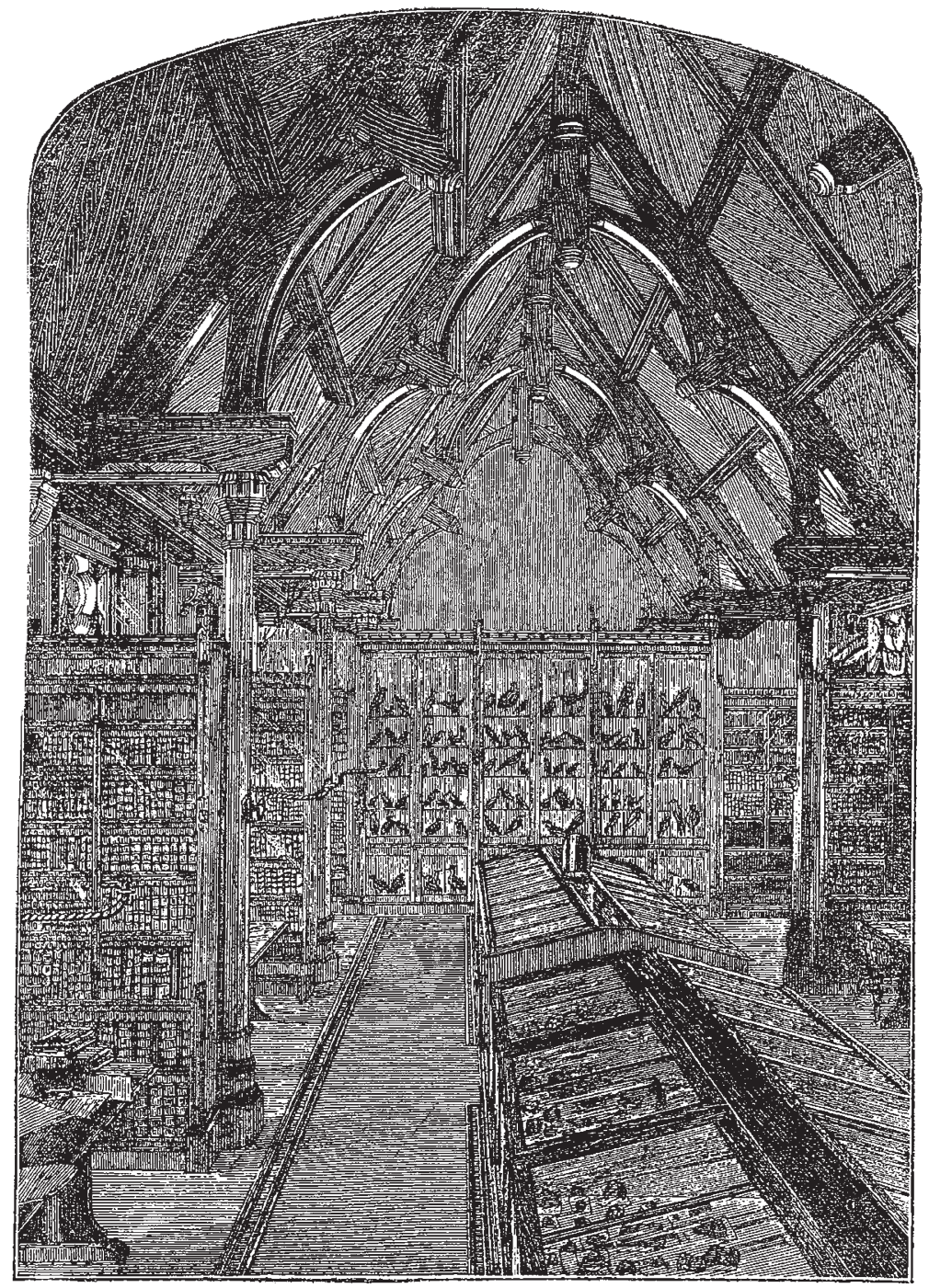

THE MUSEUN OF CLIFTON COLLEGE

dition annually in July to some place of interest in the neighbourhood.

A conversazione was given last month to celebrate the opening of the Museum and Botanic Garden. The former shares with the library the new room recently added to the school buildings by the head-master. Space being, of course, limited, it has been decided to make the collections essentially British; the local series to be as far as possible complete, and the general collections typical. Through the liberality of friends, considerable progress has been made already.' Thus the museum already contains a fine series of British plants, another fine series of typical
British fossils, nearly $r, 000$ specimens of minerals, the same number of British Lepidoptera, many British birds and their eggs, and a good typical collection of shells. The completion of the local series is left in the hands of the different sections.

The Botanic Garden is large, and is laid out in long narrow beds with grass walks between. Over I,o0o hardy herbaceous plants are here arranged according to the natural system; and new additions are being constantly made. There are also specimens of all the ornamental trees and shrubs commonly cultivated in England; and a rockery has been built for Alpine plants. 